\title{
Non-visual effects of diurnal exposure to an artificial skylight, including nocturnal melatonin suppression
}

\author{
Akira Yasukouchi $^{1 *}$, Takafumi Maeda ${ }^{1} \mathbb{D}$, Kazuyoshi Hara $^{2}$ and Hiroyuki Furuune ${ }^{2}$
}

\begin{abstract}
Background: Recently, more consideration is being given to the beneficial effects of lighting on the maintenance and promotion of the health and well-being of office occupants in built environments. A new lighting technology using Rayleigh scattering has made it possible to simulate a blue sky. However, to date, no studies have examined the possible beneficial effects of such artificial skylights. The aims of this study were to examine the non-visual effects of artificial skylights and conventional fluorescent lights in a simulated office environment and to clarify the feature effects of the artificial skylights.
\end{abstract}

Methods: Participants were 10 healthy male adults. Non-visual effects were evaluated based on brain arousal levels ( $a$-wave ratio and contingent negative variation [CNV]), autonomic nervous activity (heart rate variability [HRV]), work performance, and subjective responses during daytime exposure to either an artificial skylight or fluorescent lights, as well as nocturnal melatonin secretion.

Results: Subjective evaluations of both room lighting-related "natural" and "attractive" items and the "connected to nature" item were significantly higher with the skylight than with the fluorescent lights. Cortical arousal levels obtained from the early component of the CNV amplitude were significantly lower with the skylight than with the fluorescent lights, whereas $a$-wave ratio and work performance were similar between the two light sources. The HRV evaluation showed that sympathetic nerve tone was lower and parasympathetic nerve tone was higher, both significantly, for the skylight than for the fluorescent lights during daytime. Nocturnal melatonin secretion was significantly greater before and during light exposure at night under the daytime skylight than under the fluorescent lights.

Conclusions: Our results suggest that artificial skylights have some advantages over conventional fluorescent lights in maintaining ordinary work performance during daytime with less psychological and physiological stress. The findings also suggest that the artificial skylights would enable built environments to maintain longterm comfort and productivity.

Keywords: Artificial skylight, Fluorescent light, Office, Non-visual effect, Arousal level, Melatonin secretion

\footnotetext{
* Correspondence: physioanthropol@yahoo.co.jp

'Department of Human Science, Faculty of Design, Kyushu University, 4-9-1,

Shiobaru, Minami-ku, Fukuoka 815-8540, Japan

Full list of author information is available at the end of the article
}

(c) The Author(s). 2019 Open Access This article is distributed under the terms of the Creative Commons Attribution 4.0 International License (http://creativecommons.org/licenses/by/4.0/), which permits unrestricted use, distribution, and reproduction in any medium, provided you give appropriate credit to the original author(s) and the source, provide a link to the Creative Commons license, and indicate if changes were made. The Creative Commons Public Domain Dedication waiver (http://creativecommons.org/publicdomain/zero/1.0/) applies to the data made available in this article, unless otherwise stated. 


\section{Background}

Physiological anthropology is a field that primarily focuses on humans living in modern society. This is because humans are considered to be adapted to ancient environments, given that we spent nearly all of our history as a species in such environments, dating back to our huntergatherer stage. Thus, there must be a discrepancy between environments to which humans have already adapted and environments to which humans are struggling to adapt when seeking comfort and convenience. For this reason, physiological anthropologists study the environmental pressures on humans in highly technological environments [1-6], in which lighting must also be examined as one of the physical factors affecting environmental adaptability [7-9].

Windows give occupants in built environments feelings of connectedness to nature and help them to feel more relaxed, which boosts their health and well-being [10-13]. However, occupants in windowless environments or those who are situated away from windows have to depend on artificial light and have no connection to nature. Natural light and views from windows also enhance attention and cognition [14], whereas windowless environments or those with relatively low artificial light illumination negatively affect arousal level and productivity due to sleepiness [15]. Furthermore, there is no time-dependent variation in natural light and views throughout the day in windowless environments, which can increase psychological stress [16] and lower job satisfaction [17].

In addition to more advanced lighting technologies such as light-emitting diodes (LEDs) and organic electroluminescence (OEL), a new technology has been developed to simulate natural sunlight and blue skies. This system is composed of a light source and nanostructured material that recreates the Rayleigh scattering phenomenon that occurs naturally in the Earth's atmosphere whereby shorter wavelengths of light are strongly diffused while longer wavelengths are weakly diffused. This phenomenon can be recreated in a small box and helps people to perceive a realistic sun and blue sky with indefinite depth, even though the spectral distribution is not exactly the same as that of natural sunlight. The introduction of this artificial skylight in a windowless environment or space situated away from windows gives the impression of connectedness to nature, which should boost psychological and physiological well-being and health.

Canazei et al. [18] determined, using a questionnairebased approach, that an artificial skylight similar to the one used in this study had beneficial effects compared with conventional fluorescent lighting. However, in addition to psychological effects, physiological responses caused by nonvisual effects or non-image-forming effects should also be considered to improve worker health, well-being, and productivity [15, 19-23]. Ours is the first study to examine the non-visual effects of artificial skylights in a simulated office environment. The existence of non-visual effects was suggested when the retinohypothalamic tract was first identified [24] and, as a non-visual effect, light-induced nocturnal melatonin suppression was first reported by Lewy et al. [25]. Brainard et al. [26] and Thapan et al. [27] have reported the peak spectral sensitivity of light-induced melatonin suppression at night, with the peak located at around the blue part of light, which was soon further supported by the discovery of intrinsically photosensitive retinal ganglion cells (ipRGCs) [28]. There are several important neural sites from the retina to the pineal body via the hypothalamus that are related to circadian rhythms, autonomic nervous activity, endocrine secretion, cortical arousal level, and muscle tension. These are called "non-visual effects" and are associated with signal input to ipRGCs projected to the retinohypothalamic tract. The intensity, wavelength, duration, timing, and pattern of light are important factors affecting photic resetting of non-visual effects [29], particularly in terms of the circadian system and suppression of melatonin secretion. Thus, changes in physiological function caused by the light environment would affect the productivity, comfort, and well-being of office workers, not only as an acute effect, but also as a long-term effect.

The aims of this study were to examine the cortical arousal level, autonomic nervous activity, and nocturnal melatonin secretion, as well as work performance and subjective evaluations, of participants exposed to artificial skylights and conventional fluorescent lights in a simulated office and to clarify the feature effects of the artificial skylight.

\section{Methods}

\section{Participants}

Participants were 10 healthy male college students (mean age \pm standard deviation, $23.6 \pm 0.7$ years). They were enrolled in the study after completing a psychological interview and screening for sleep disorders, medication use, recent night work, and recent overseas travel across time zones. This study was approved by the Ethics Committee of the Faculty of Design, Kyushu University. Written informed consent was obtained from all participants prior to enrollment. Participants were required to keep a regular 8-h sleep schedule for at least 5 days before the experiment, which was confirmed from their daily sleep diary and actigraph data (Actiwatch-L; Mini-Mitter Co., Inc., Bend, OR). Participants were also asked to refrain from using caffeine, nicotine, and alcohol for 1 day before the experiment.

\section{Experimental protocol}

A climatic chamber at the Faculty of Design, Kyushu University, was used for our study from November to 


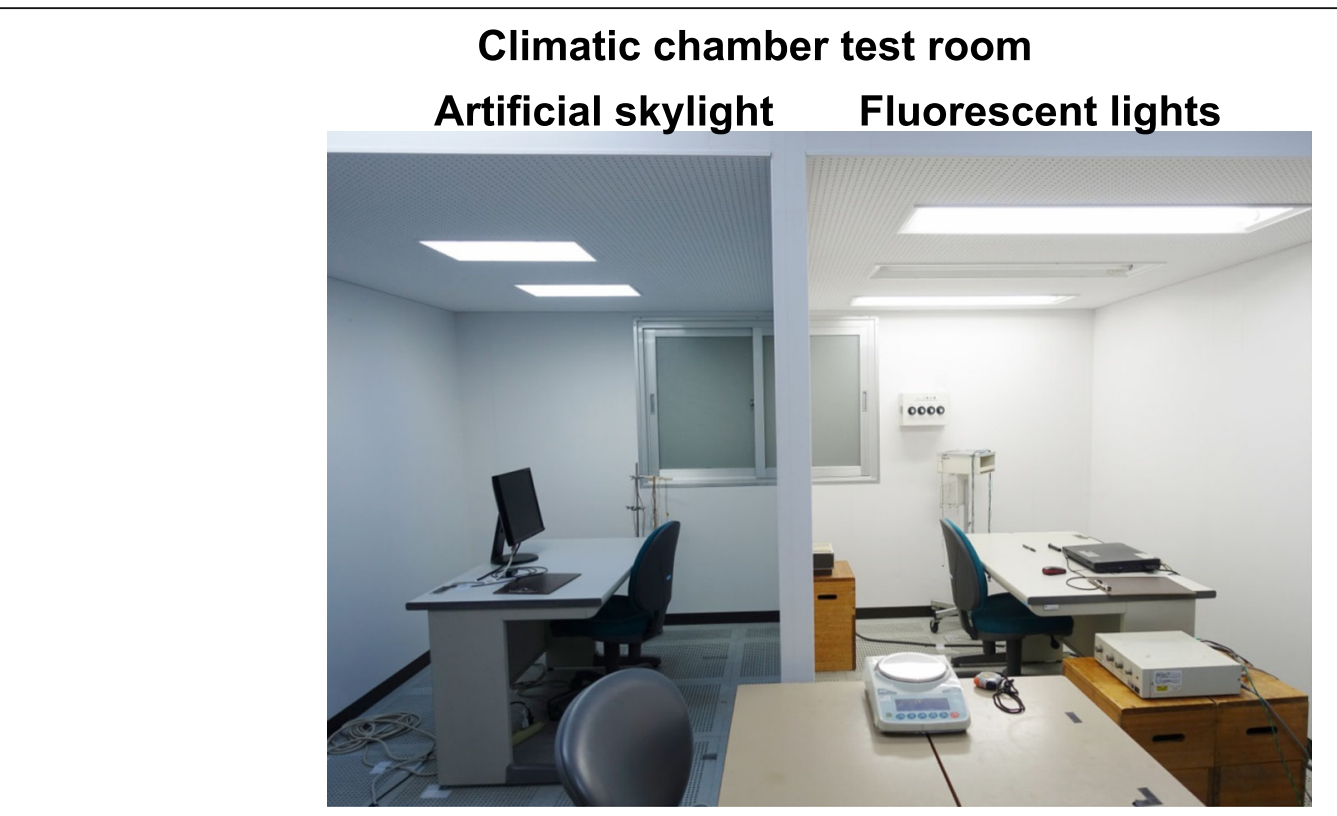

Fig. 1 On the left is the room with artificial skylights; the room with fluorescent lights is shown on the right

December 2017. Two simulated office environments with identical areas (width, $1960 \mathrm{~mm}$; length, $2700 \mathrm{~mm}$; height, $1940 \mathrm{~mm}$ ) were set up as shown in Fig. 1. The ambient temperature in each room was kept at $25 \pm$ $0.04{ }^{\circ} \mathrm{C}$ with $50 \pm 0.10 \%$ relative humidity. The artificial skylight room (CoeLux ST, CoeLux S.r.L) is shown on the left side of the figure, and the fluorescent lightroom is shown on the right side.

The lighting conditions of illuminance and correlated color temperature (CCT) when horizontal illuminance was set as the same light intensity measured on the desk (440 lx) are described in Table 1. The work plane is where the most important tasks in the office occur and because the relevant guidelines in each country generally recommend that horizontal illuminance be measured on the desk. The melanopic illuminance obtained from corneal spectral irradiance measures calculated by the equation of Lucas et al. [30] determined 4.99 melanopic lx with skylights, which is about $35 \%$ greater than the 3.70 melanopic lx with fluorescent light. In addition, cyanopic, rhodopic, chloropic, and erythropic illuminances were also $22 \%$, $22 \%, 8 \%$, and $0 \%$ higher with skylights, respectively. An artificial skylight installed on the ceiling is shown in Fig. 2,

Table 1 Lighting conditions of the artificial skylights and fluorescent lights

\begin{tabular}{llllll}
\hline & \multicolumn{2}{l}{ Measured on the desk } & & \multicolumn{2}{l}{ Measured at the cornea } \\
\cline { 6 - 7 } \cline { 6 - 7 } & Illuminance $(\mathrm{Ix})$ & $\mathrm{CCT}(\mathrm{K})$ & & Illuminance $(\mathrm{Ix})$ & CCT (K) \\
\hline AS & 440 & 6700 & & 417 & 6200 \\
$\mathrm{FL}$ & 440 & 4800 & & 330 & 4800 \\
\hline
\end{tabular}

CCT correlated color temperature, AS artificial skylight, FL fluorescent lights and the spectral power distributions of the skylights and fluorescent lights are shown in Fig. 3.

All measurement items and timings are shown in Fig. 4, and the schedule is shown in Fig. 5. Participants arrived at the laboratory before 09:00 and wore $t$-shirts and shorts to homogenize the thermal conditions.

After we set the sensors to take measurements until 09:50, a subjective evaluation of the lighting in the room was made and the first task was started. The simulated office tasks consisted of a contingent negative variation (CNV) paradigm and arithmetic task. Both tasks were performed for 36 min with a 3-min rest and interval as a single set (Fig. 4). The set of tasks was performed twice each morning and twice each afternoon (Fig. 5). The measurement timing of $\alpha$-wave ratio, heart rate variability (HRV), and subjective evaluation in a set are shown in Fig. 4. The early component of the CNV amplitude and the selective response time were measured during the CNV paradigm, and the number of answers and ratio of correct answers were obtained during the arithmetic task. HRV was not measured before the CNV paradigm in the second set each morning and afternoon.

As shown in Fig. 5, the first and the second task sets started at 10:00 and 11:00 in the morning and at 13:30 and 14:30 in the afternoon, respectively, and were followed by free time until 18:00. The participants were permitted to read books, watch videos, and play games that did not overly stimulate them during the free-time periods after 15:00 and 19:00. The display was set to 0.5 $\mathrm{cd} / \mathrm{m}^{2}$ during the videos and games so as to not affect melatonin secretion, in accordance with Higuchi et al. [31]. The lighting conditions were as shown in Table 1 


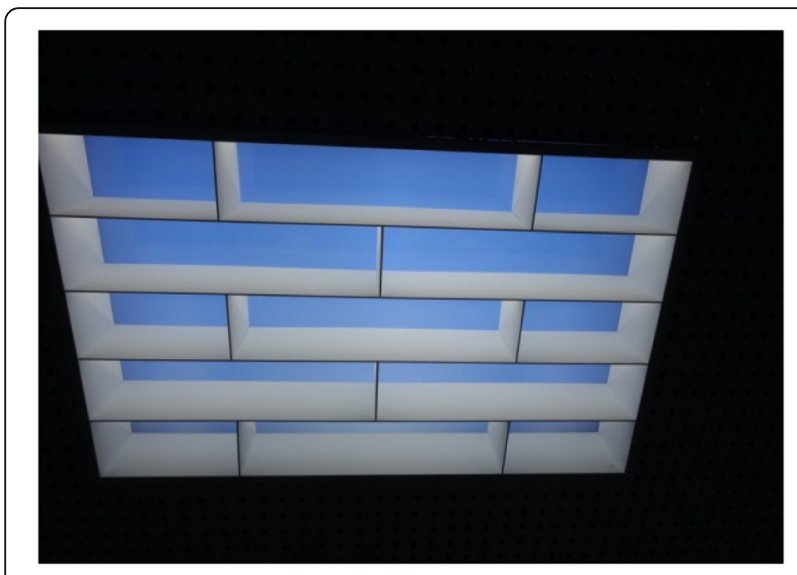

Fig. 2 Artificial skylight seen from below

during the period of office simulation from 10:00 to 18: 00 , set at $200 \mathrm{~lx}$ measured on the desk for each light source shown in Table 1 during the evening meal and shower period from 18:00 to 19:00, and emitted dim light $(<30 \mathrm{~lx})$ during the free period from 19:00 to 00: 00. Saliva samples were taken five times (solid circles in Fig. 5) from 23:00 to 01:30 for analysis of melatonin concentrations. During this period, participants, regardless of the light source condition during the daytime, were exposed to fluorescent light at $500 \mathrm{~lx}$ and $5000 \mathrm{~K}$ from 00:00 to 01:30 to evaluate light-induced nocturnal melatonin suppression. The experiment was then finished.

\section{Measurements}

\section{Contingent negative variation}

$\mathrm{CNV}$, one of the event-related potentials in the brain, was first proposed by Walter et al. [32], who suggested that the components of the CNV reflect attention and expectancy related to a given stimulus as well as arousal level as a fundamental function. In this study, electroencephalography (EEG) was measured by using Ag$\mathrm{AgCl}$ disc electrodes located at $\mathrm{Fz}, \mathrm{Cz}$, and $\mathrm{Pz}$ according to the International 10-20 system with a linked ear reference (Polimate AP1000; TEAC Co. Ltd., Tokyo, Japan). The CNV paradigm consisted of a warning stimulus (S1) and imperative stimulus (S2) with a 2500ms interval. The paradigm was repeated 44 times over $15 \mathrm{~min}$, and the inter-trial interval was randomized between 8000 and $12000 \mathrm{~ms}$. The baseline level was obtained from the averaged potential during the $500 \mathrm{~ms}$ before the S1 stimulus. The arithmetic mean of the early component of the $\mathrm{CNV}$ amplitude was obtained between 500 and $1000 \mathrm{~ms}$ from the S1 stimulus during the 44 trials with the exclusion of trials with noise due to eye movement or blinking detected by electrooculography. The imperative stimulus (S2) consisted of a red circle as a target signal and a green circle as a nontarget signal; target signals appeared in $70 \%$ of all trials. The participant was requested to push the button as soon as possible upon recognizing the red signal of S2 on the display.
Measurement point:

\section{Orange area on desktop plane}

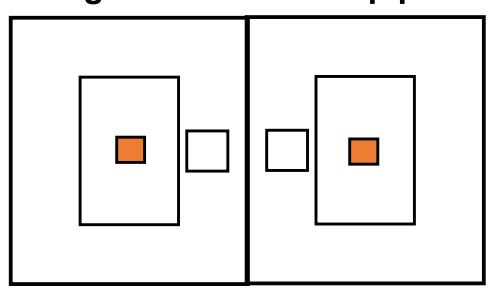

AS

FL

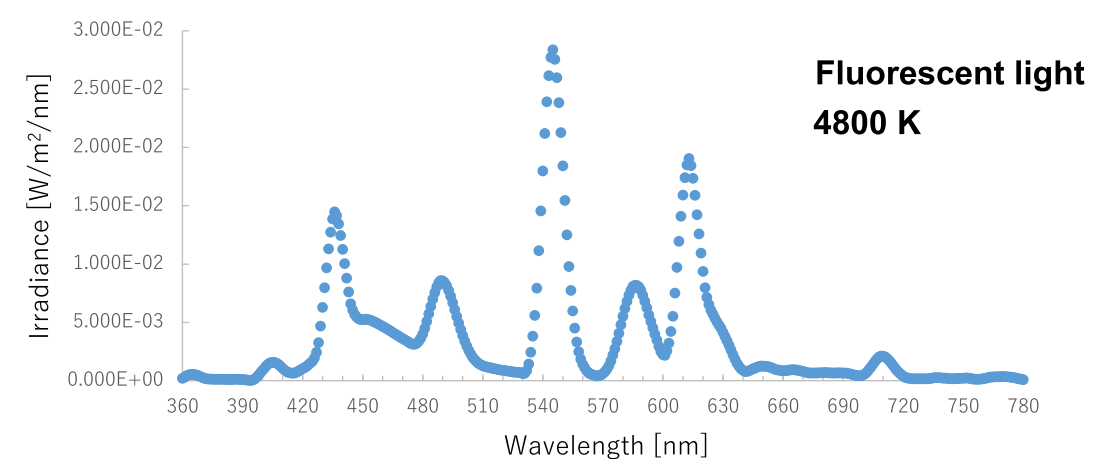

Fig. 3 Spectral distribution of the artificial skylight (upper) and the fluorescent lights (lower). The wavelength region around 480 nm is where photoreceptors related to non-visual effects (ipRGCs) have high sensitivity. AS, artificial skylight; FL, fluorescent lights 


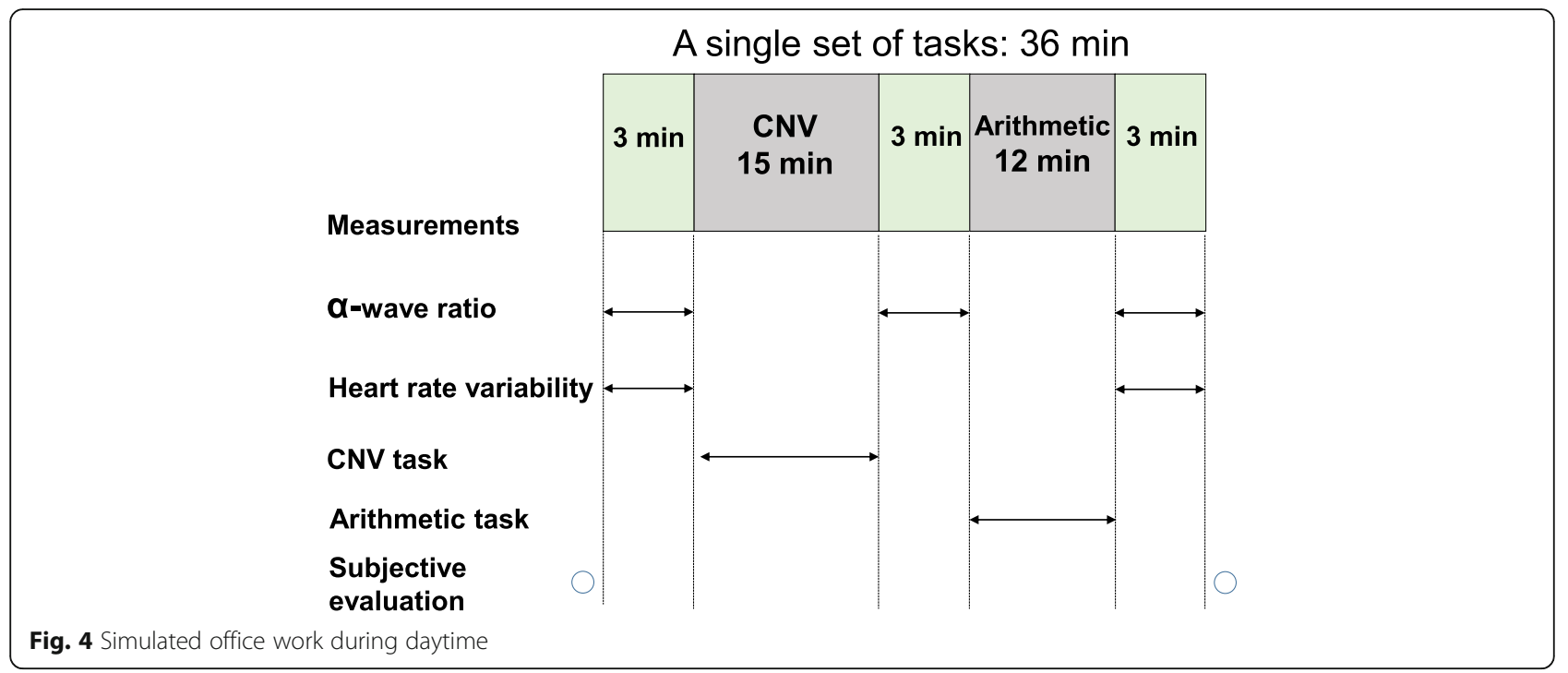

\section{Work performance}

The average response times of correct answers during the $\mathrm{CNV}$ paradigm were considered measures of work performance. The arithmetic task was a single-digit addition task in which participants were asked to add neighboring digits for $12 \mathrm{~min}$, and the number of answers and the ratio of correct answers were considered to reflect work performance.

\section{a-wave ratio}

The spontaneous EEG at $\mathrm{Pz}$ was measured for $3 \mathrm{~min}$ (Fig. 4) with participants at rest sitting on a chair with their eyes open. The power values for the $\alpha$ wave $(8-13 \mathrm{~Hz})$ and $\beta$-wave $(13-30 \mathrm{~Hz})$ were calculated from a fast Fourier transform (FFT) of the EEG data. The relative power value of the $\alpha$-wave ( $\alpha$-wave ratio) was obtained by $\alpha \mathrm{rp} /(\alpha \mathrm{rp}+\beta \mathrm{rp}) \times 100$, where $\mathrm{rp}$ is the relative power value.

\section{Heart rate variability}

Participants were asked to gaze at a point on the wall in front of them. Their breathing was controlled at 15 breaths/min with a metronome while an electrocardiogram (ECG) from bipolar chest leads was measured before the CNV paradigm and after the arithmetic task in each task set (Fig. 4). The R-R interval obtained from the ECG data was analyzed by the FFT technique with MaP1060 Ver5.16 (Nihonsanteku Co., Ltd., Osaka, Japan) and the powers of the high-frequency ( $\mathrm{HF}, 0.20-0.35 \mathrm{~Hz}$ ) and low-frequency (LF, 0.05-0.20 Hz) components were calculated to evaluate autonomic nervous activity. LF/HF and $\mathrm{HF} /(\mathrm{LF}+\mathrm{HF})$ were considered measures of sympathetic and parasympathetic nerve tones, respectively.

\section{Melatonin}

Saliva samples obtained with a Salivette saliva collector (Sarstedt AG \& Co. KG, Sarstedt, Germany) were

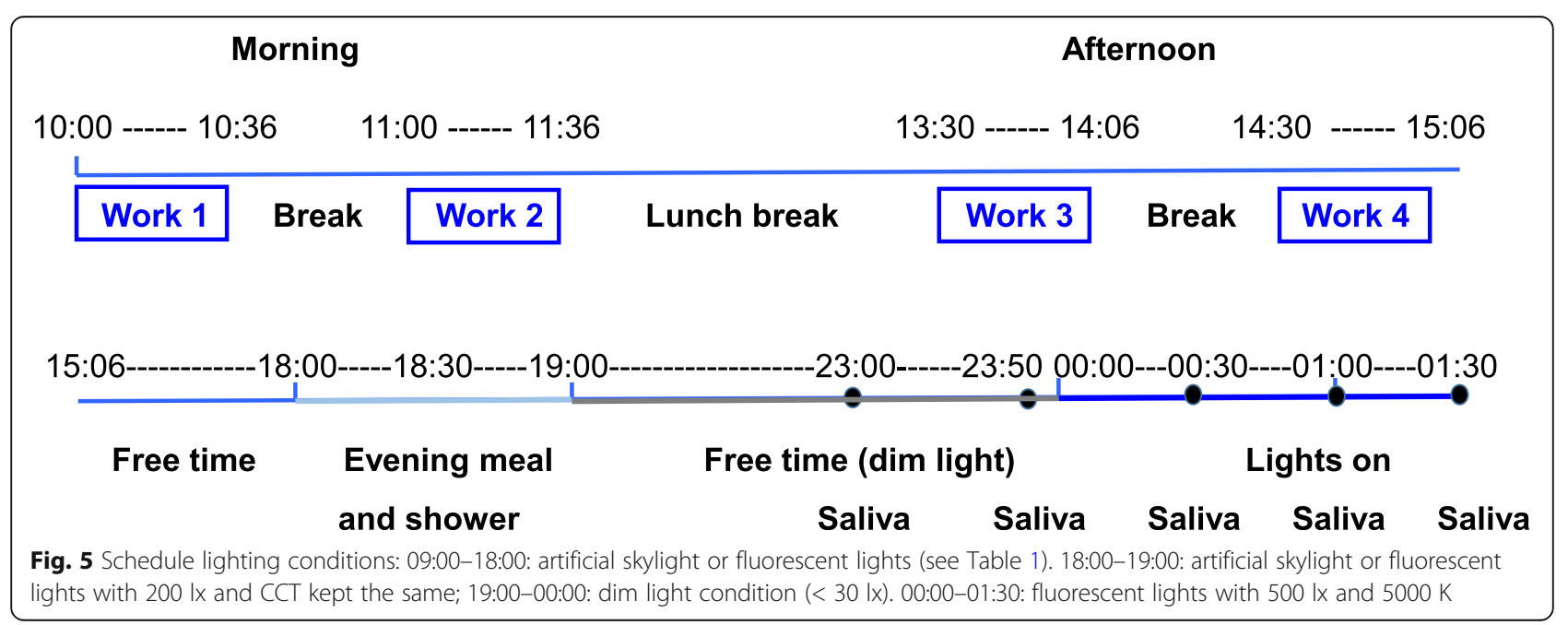


centrifuged for $5 \mathrm{~min}$ at $1000 \mathrm{rpm}$, frozen at $-20{ }^{\circ} \mathrm{C}$, and stored until assayed. The melatonin levels of the samples were analyzed in duplicate with a commercially available RIA kit (Direct Saliva Melatonin RIA, RKDSM2; BÜHLMANN Laboratories AG, Schönenbuch, Switzerland). The mean values of duplicates were used for the analysis.

\section{Subjective evaluation}

The questionnaires used in Canazei et al. [18] consisted of 38 room atmosphere-related terms, 6 room lightingrelated terms, and 1 item of connectedness to nature. Our study used the same questionnaires of room lighting and connectedness to nature and selected 7 of the 38 room atmosphere-related terms that were found to have significant main effects of light and time by Canazei et al. [18].

Each questionnaire is detailed below.

1) Room atmosphere questionnaire

- Seven atmosphere terms: threatening, cozy, active, uninhibited, safe, restless, and stimulating

- Rating categories and numerical coding: 1 , "not at all"; 2, "a little"; 3, "rather"; and 4, "very"

2) Room lighting questionnaire

- Six room lighting-related bipolar adjective pairs: pleasant-unpleasant, attractive-unattractive, natural-artificial, glary-without glare, dim-bright, and even-uneven

- Numerical ratings from 0 to 5

3) One item of connectedness to nature

- Rating categories and numerical coding: 1 , "not at all"; 2, "a little"; 3, "rather"; and 4, "very"

\section{Statistical analysis}

Types of light sources and time were used as the variables of each measurement, and two-way analyses of variance were conducted with Bonferroni correction using SPSS version 22.0 (SPSS Inc., Chicago, IL, USA). Differences with $p<0.05$ were considered statistically significant.

\section{Results}

Brain arousal levels were evaluated by the $\alpha$-wave ratio and early component of the CNV amplitude. The $\alpha$-wave ratio is the arousal level in response to non-specific multiple stimuli around participants, whereas the early component of the CNV amplitude is the arousal level in response to specific serial events occurring during the
$\mathrm{CNV}$ paradigm. There was no significant difference in the $\alpha$-wave ratio between the two lighting conditions. However, the early components of $\mathrm{CNV}$ amplitudes were significantly higher at both $\mathrm{Fz}$ and $\mathrm{Cz}$ under the fluorescent lights than under the artificial skylights (Fig. 6; both $p$ $<0.05)$ with no time variation.

Regarding productivity measured by the arithmetic task (number of answers and ratio of correct answers) and the selective response time obtained during the $\mathrm{CNV}$ paradigm, no significant differences were observed. Lighting conditions had no effect on calculation and selective response times that required concentration, cognition, and judgment.

Sympathetic and parasympathetic nervous activities, obtained from HRV, are shown in Figs. 7 and 8, respectively. Sympathetic nervous activity for overall measurements in the daytime indicated significant effects of light and time (both $p<0.01$ ). Although there was no difference before the first task in the morning (morning 1 in Fig. 7), the difference became more evident throughout the day and was still present at afternoon 1 before the first task in the afternoon, showing that the activity was significantly lowered under the artificial skylights compared with the fluorescent lights. In the same manner, a significant effect of light on parasympathetic nervous activity was observed, with enhanced activity under the artificial skylights compared with the fluorescent lights $(p<0.05)$.

Nocturnal melatonin secretion is shown in Fig. 9. Melatonin secretion was measured at 23:00 and 23:50 under dim light conditions $(<30 \mathrm{~lx})$ and at 00:30, 01:00, and 01:30 during fluorescent light exposure (500 lx and $5000 \mathrm{~K})$. There were significant main effects of light and time (both $p<0.05$ ). According to multiple comparisons by Bonferroni correction, no difference was found at 23: 00. However, a significant difference was evident $50 \mathrm{~min}$ later under dim light conditions; this difference was greater in the participants exposed to the artificial skylights $(p<0.05)$. The difference continued even during light exposure.

Regarding subjective responses, there were significant main effects of light both for room lighting-related effects and connectedness to nature, showing that participants considered artificial skylights more "attractive" and more "natural" (both $p<0.01$ ) than fluorescent lights among the 6 items of room lighting-related effects and also felt greater connectedness to nature $(p<0.01)$ (Fig. 10). However, no significant changes with time were found for all three subjective items.

\section{Discussion}

There has been considerable focus on green construction and environmental sustainability in recent years, but relatively little attention has been paid to biological 


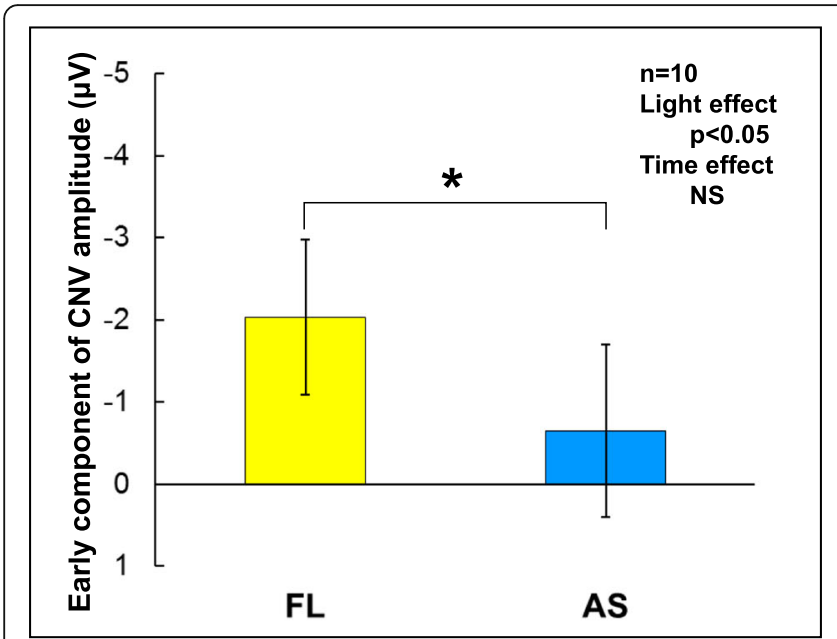

Measurement at Fz

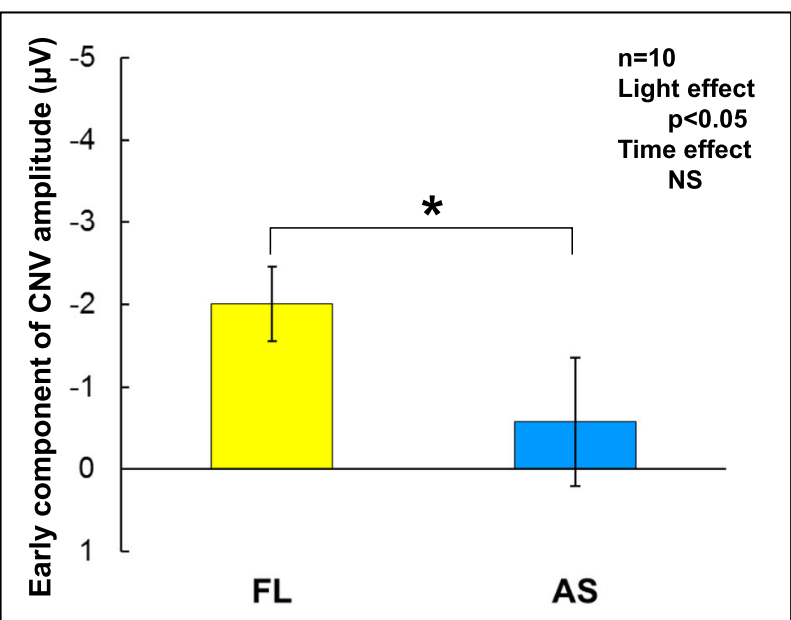

Measurement at $\mathbf{C z}$

Fig. 6 Early component of CNV amplitude obtained from Fz and Cz. A larger negative value indicates higher arousal. AS, artificial skylight; FL, fluorescent lights

sustainability. Studies of occupant health and well-being in built environments have recently begun to be conducted. It has been demonstrated that light, in addition to air and water quality, has a strong effect on occupant health and well-being in offices, not only from the point of view of subjective comfort, but also in terms of objective aspects or non-visual effects [15, 19, 21, 33].

A newly developed artificial skylight was examined here, although its spectral distribution is not exactly the same as that of natural sunlight. The aims of this study were to examine the non-visual effects of lights in terms of cortical arousal levels, autonomic nervous activity, and nocturnal melatonin secretion; to examine work productivity and subjective responses during diurnal exposure to artificial skylights and conventional fluorescent lights in a simulated office environment; and to evaluate whether artificial skylights should be favored in offices from the viewpoint of adaptability to diurnal light.

\section{Subjective evaluations}

Canazei et al. [18] were the first to perform subjective comparisons of artificial skylights and fluorescent lights in a simulated office environment built in a laboratory. They investigated subjective responses by using questionnaires, which consisted of 38 room atmosphererelated terms, 6 room lighting-related terms, and 1 item of connectedness to nature. Our study used the same

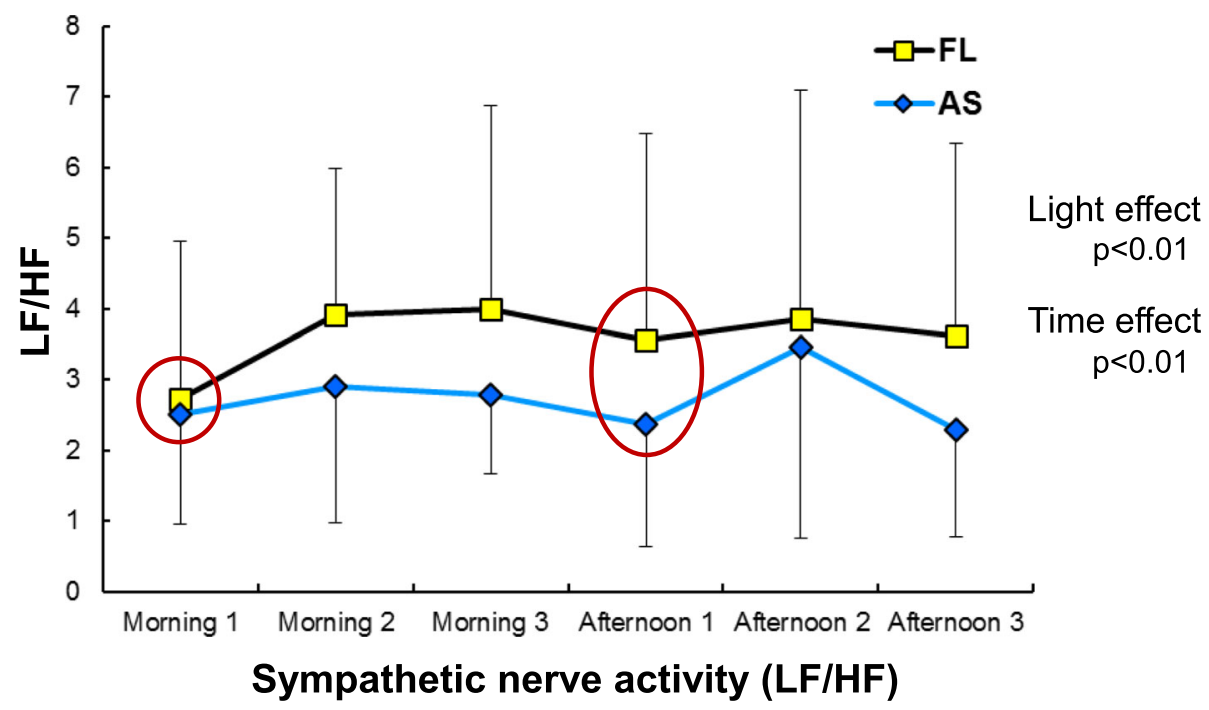

Fig. 7 Sympathetic nervous activity (LF/HF) evaluated from heart rate variability (HRV). AS, artificial skylight; FL, fluorescent lights 


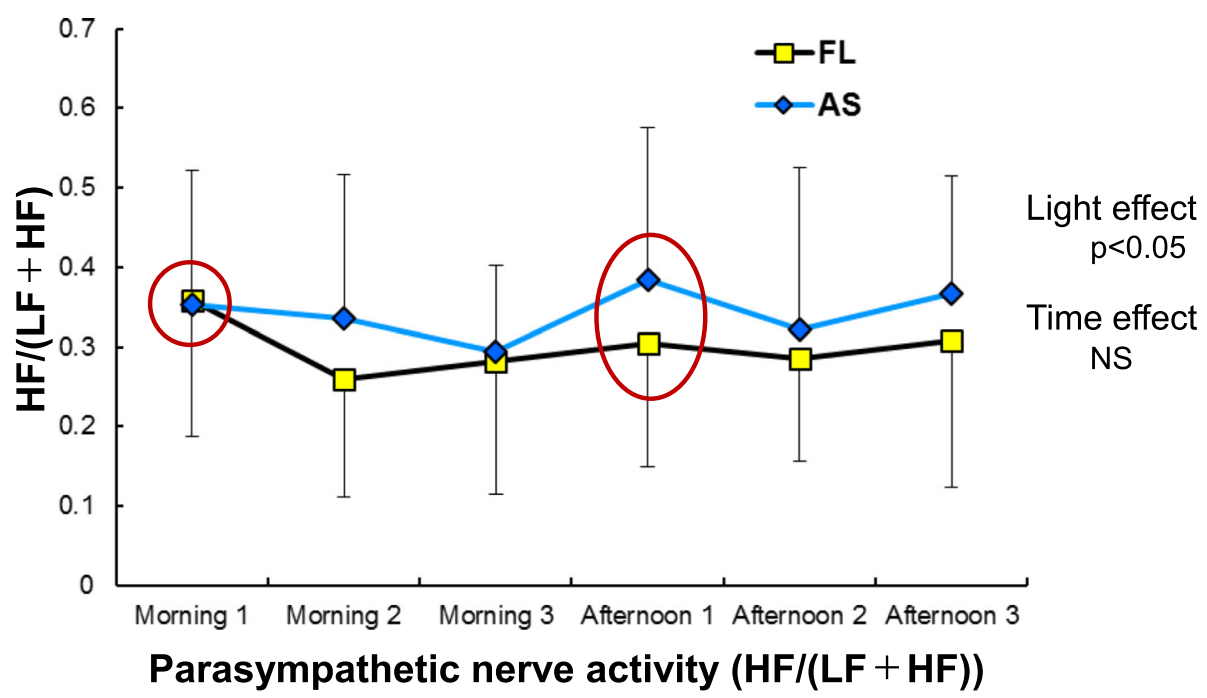

Fig. 8 Parasympathetic nervous activity $(\mathrm{HF} /(\mathrm{LF}+\mathrm{HF}))$ evaluated from heart rate variability (HRV). AS, artificial skylight; FL, fluorescent lights

items related to room lighting and connectedness to nature, and we selected 7 of the 38 room atmosphererelated items found to exert significant main effects of light and time in Canazei et al. The artificial skylight in their study was much larger size and had a higher light intensity (1215 lx) than our skylights $(400 \mathrm{~lx})$. However, significant effects were obtained from two terms-"attractive" and "nature"-of perceived room lighting and connectedness to nature; no significant effects were found among the 7 items of perceived room atmosphere in our study. Thus, these 3 items showing significant effects even at around $400 \mathrm{~lx}$ might be the features of skylights that mimic natural blue sky with indefinite depth.

\section{Non-visual effects}

Many studies have focused on the non-visual effects of light $[7,34]$, with application studies showing its beneficial effects on human health and well-being and how to translate scientific findings into office lighting designs $[15,19,22,23]$. Non-visual responses include almost all physiological functions affected by photic signals from ipRGCs projected to all major retinorecipient parts of the brain $[28,35]$. From the viewpoint of the relationship between CCT and the action factors on circadian rhythm, non-visual responses are dependent on the physical nature of light, such as its intensity and spectral distribution, and not on the type of light source [36]. In this study, the non-visual effects of artificial skylights

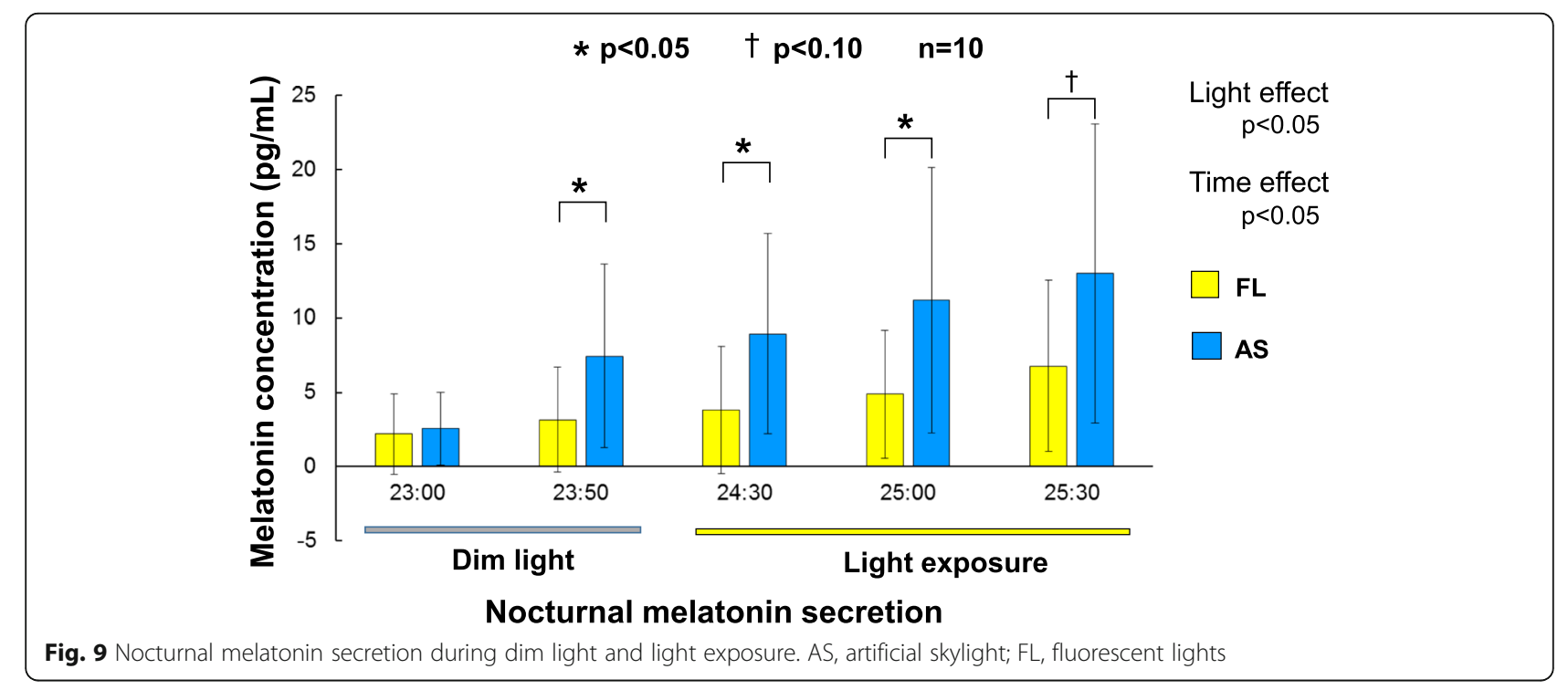




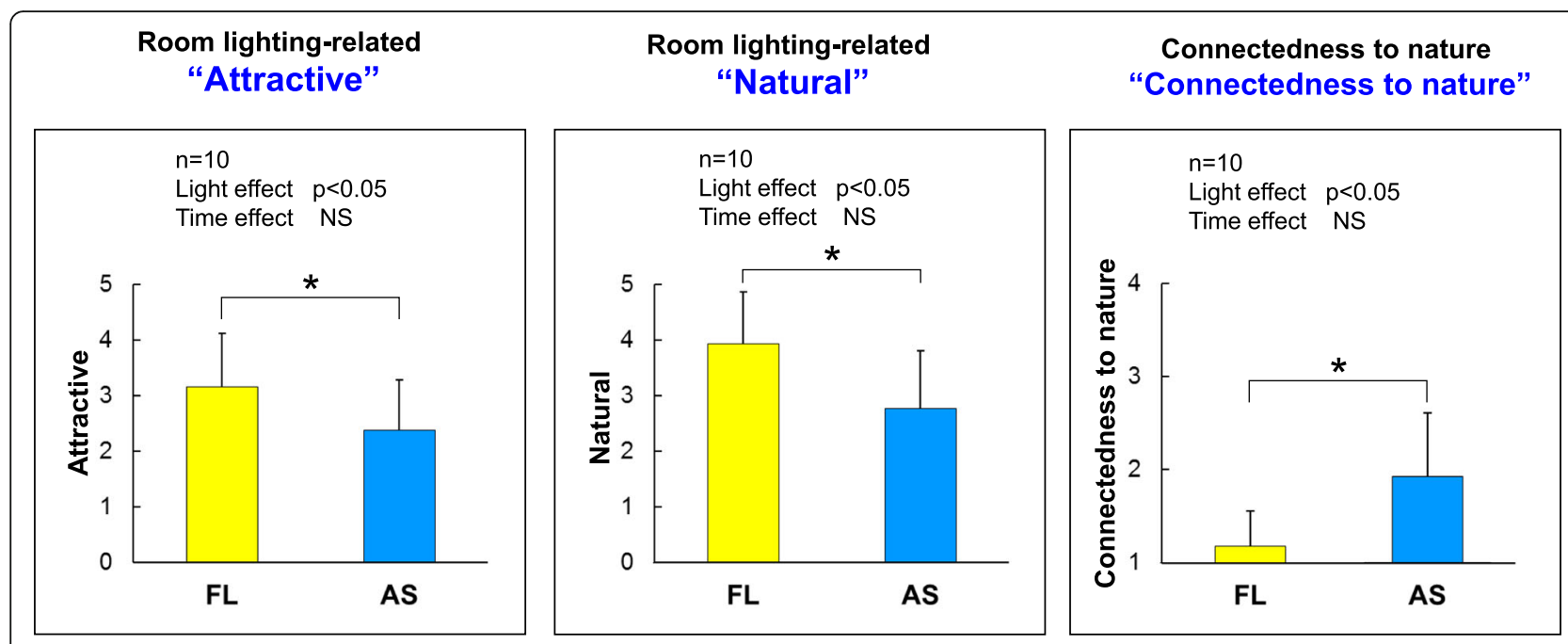

Fig. 10 Subjective evaluations. The vertical scales of left and middle graphs show that lower values are more attractive and natural, respectively, and the right shows that higher value indicates more connectedness. AS, artificial skylight; FL, fluorescent lights

and conventional fluorescent lights during daytime exposure were evaluated in terms of arousal level, autonomic nervous activity, and nocturnal melatonin secretion. The arousal level of the brain and autonomic nervous tension are thought to be associated with office work productivity. Nocturnal melatonin secretion, which affects sleep and circadian rhythms, might also have an indirect effect on long-term work performance.

Regarding arousal levels, the $\alpha$-wave ratio and the early component of the CNV amplitude were measured. The $\alpha$-wave ratio was obtained from spontaneous EEG immediately before the CNV paradigm was begun and represents the arousal level with non-specific stimulation. The CNV, one of the event-related potentials, has been evaluated as expectancy [32] and motivation [37] while the early component of the $\mathrm{CNV}$ amplitude has been considered the attention or arousal level with the specific serial events of warning, imperative stimuli, and button pushing [38]. This type of attention is called the phasic arousal level [39].

\section{Arousal level or alertness}

There have been many studies on alertness involving spontaneous EEG evaluation. These studies have reported that alertness and cortical arousal level were increased by monochromatic blue light and daylight with a higher CCT in the case of polychromatic light [40-44]. However, there was no significant difference in the $\alpha$ wave ratio in this study between the two types of light studied, showing that the arousal level with non-specific stimulation was the same under the two lighting conditions.

On the other hand, the early component of the CNV amplitude or the phasic arousal level measured at both
$\mathrm{Fz}$ and $\mathrm{Cz}$ was significantly lower under the artificial skylights than under the fluorescent lights. It might be speculated that the artificial skylights would increase sleepiness and lower work productivity. However, there was no increase in the $\alpha$-wave ratio reflecting increased sleepiness. In addition, the work performance of the selective response time and arithmetic task did not reveal any differences between the two lighting conditions. The results suggested that individuals under artificial skylights would have the same work performance as those under fluorescent lights with a lower phasic arousal level and same sleepiness. In other words, occupants under the fluorescent lights might have a slightly excessive tension of arousal level when achieving the same work compared with those under the artificial skylights [45].

Deguchi and Sato [46] were the first to report the effect of the CCT of light on the early component of the $\mathrm{CNV}$ amplitude. They evaluated phasic arousal levels under CCT conditions of $3000 \mathrm{~K}, 5000 \mathrm{~K}$, and $7500 \mathrm{~K}$ with the same light intensity of $1000 \mathrm{~lx}$. Their results showed that the simple response time during the CNV paradigm was not significantly affected by CCT while the early component of the CNV amplitude was significantly higher with $7500 \mathrm{~K}$ of light than with $3000 \mathrm{~K}$. Subsequent studies also demonstrated the same results, namely, that a higher CCT enhanced the arousal level obtained by the CNV paradigm [47, 48]. Because ipRGCs are sensitive to short-wavelength light, a higher CCT with a greater amount of short-wavelength energy is considered to strengthen non-visual effects [26, 28, 30]. However, the phasic arousal level was significantly lower in the participants exposed to the artificial skylights than in those exposed to the fluorescent lights, even though the CCT and light intensity of the lights 
measured at the occupant's eye level in this study were higher under the artificial skylights (417 lx with $6200 \mathrm{~K}$ ) than under the fluorescent lights (330 lx with $4800 \mathrm{~K}$ ). This finding is different from that of other studies.

The non-visual effect is supposed to be affected not only by direct photic stimulation to ipRGCs, but also integrated signal input to ipRGCs from rods and S, M, and $\mathrm{L}$ cones in the retina. Because the integration process is not completely understood, the non-visual effects cannot be entirely explained by the intensity and CCT of light $[30,49]$. It is implied that the results obtained with the different spectral distributions of the two light sources in this study could be affected by differences in the integration of signals from the five photic receptors. However, the cause is unknown. Different types of light sources were used in this study, whereas many other studies have used the same light source to specifically examine CCT and/or intensity effects. Therefore, one of the possible reasons for the conflicting result might be an impact on the psychological impression of the artificial skylights. Non-visual effects were originally considered independent of visual effects or psychological responses to a view, and yet, it was very likely that the psychological effects of an artificial skylight with no glare and indefinite depth would reduce tension to a moderate level because the skylight gives occupants comprehensive feelings of a natural atmosphere and connectedness to nature. Thus, although the differences in the light sources themselves were believed to not affect nonvisual effects [36], the impact on psychological factors might overlap with non-visual functions.

\section{Autonomic nervous activity}

In terms of autonomic nervous activity, it is generally considered that sympathetic nerve tone becomes dominant over parasympathetic tone immediately before and during mental work. Some studies have examined the effect of the CCT of light on autonomic nervous activity evaluated using HRV [50, 51], blood pressure [52], and body temperature $[53,54]$. These studies reported that a higher CCT strengthens sympathetic nerve tone or both sympathetic and parasympathetic tones.

In the case of autonomic nerve tone related to cardiac activity evaluated from HRV in this study, the sympathetic nerve tone (LF/HF) was significantly lower under the artificial skylight conditions than under the fluorescent light conditions when all of the daytime data were pooled ( $p<0.01$; Fig. 7). Similarly, parasympathetic tone $(\mathrm{HF} /(\mathrm{LF}+\mathrm{HF}))$ was significantly higher with the skylight $(p<0.05$; Fig. 8). Thus, our results indicate lower autonomic nerve tension with the skylight than with the fluorescent lights, despite the higher CCT of the skylight. This finding also conflicts with those of previous reports. As shown in Figs. 7 and 8, both sympathetic and parasympathetic nerve tones were similar for the two types of lights immediately before the first CNV paradigm at morning 1; the tension in the fluorescent light condition tended to increase at mornings 2 and 3, with the tendency continuing into the afternoon and being even higher at afternoon 1 immediately before the CNV task. These results suggest that consistent work performance with less tension, evaluated not only from the early component of the CNV amplitude but also from HRV, could be maintained with the artificial skylights, despite the higher CCT of skylights. These findings again imply that differences in psychological responses might have affected non-visual effects, as seen in the phasic arousal level and autonomic nervous activity.

\section{Nocturnal melatonin secretion}

Although few studies have investigated the effects of light exposure in daytime on non-visual responses at night, these reports have shown effects on nocturnal melatonin secretion [55], dim light melatonin onset (DLMO) [56], and sleep quality [57, 58]. Therefore, it was expected that the melatonin secretion measured in this study would also provide information on how different light sources in daytime affect nocturnal melatonin secretion, DLMO, and sleep quality. It was anticipated, for example, that the more endogenous the melatonin secretion before sleep, the greater the improvement in sleep quality [59-62]. The increased melatonin secretion before sleep might be caused by advanced DLMO or secretion activation by light exposure in the morning. The previous studies showed that the higher intensity and/or CCT of light in the morning, the smaller the lightinduced nocturnal melatonin suppression and the more advanced the circadian rhythm phase (DLMO) $[15,55$, 63]. There might be psychological effects that occurred in daytime due to different light sources. However, only fluorescent lights were used at night when melatonin secretion was evaluated. If any differences in melatonin secretion were found, they would be caused specifically by the difference in physical features of light sources used in the daytime. The melatonin secretion was measured at 23:00 and 23:50 (dim light condition < $30 \mathrm{~lx}$ ) before participant exposure to fluorescent lights, with the results indicating that melatonin secretion at 23:50 was significantly increased under daytime skylight conditions than under fluorescent conditions; no difference in melatonin secretion between the two lighting conditions was observed at 23:00 (Fig. 9). Furthermore, the melatonin secretion obtained at 00:30 and 01:00 during light exposure at $500 \mathrm{~lx}$ with $5000 \mathrm{~K}$ was found to be significantly higher in those exposed to the artificial skylights than in those exposed to the fluorescent lights, with the tendency maintained until 01:30 (Fig. 9). The melanopic illuminance was 4.99 melanopic lx with skylights, which 
is about $35 \%$ greater than the 3.70 melanopic $\mathrm{lx}$ with fluorescent light. In addition, cyanopic, rhodopic, chloropic, and erythropic illuminances were also $22 \%, 22 \%, 8 \%$, and $0 \%$ higher, respectively, with the skylight. It is unclear how interactions of photoreceptive units (cones [L, $\mathrm{M}, \mathrm{S}]$, rods, and ipRGCs) activate ipRGCs. However, the following features of ipRGCs are known [30]: (1) the fundamental light response is an irradiance-dependent increase in firing, (2) they are less sensitive than rods or cones (which means greater stimulation is needed), and (3) once the threshold for ipRGC activation has been reached, activation is remarkably persistent over a long duration of constant illumination. Therefore, it is speculated that, in addition to higher CCT with skylight, these integrated photoreceptor inputs might contribute to increased nocturnal melatonin secretion and/or an advanced DLMO shift. Our findings suggest that the use of artificial skylights in office environments might help to maintain a constant circadian rhythm when advanced DLMO actually occurs because the circadian rhythm is generally slightly longer than $24 \mathrm{~h}$ and ordinary exposure to light at night additionally delays DLMO. Our results also suggest that skylights have a weak effect on lightinduced nocturnal melatonin suppression even with a higher light intensity (500 lx) than that found in ordinary homes. This might also contribute to sleep improvement, as demonstrated by our previous polysomnography study showing that higher melatonin secretion before sleep could lead to a longer period of stage 4 sleep [58].

\section{Conclusions}

Artificial skylights that simulate natural sunlight and blue skies help to maintain appropriate work performance with lower psychological and physiological stress and promote consistent long-term work productivity with comfort and good health from the point of view of increased nocturnal melatonin secretion and/or an advanced shift in circadian rhythms.

\section{Acknowledgements}

We have many thanks to Mr. S. Moritsubo, Mr. M. Hayashi, and Ms. S. Shin for their support to conduct our experiments and are grateful to all the participants of this study.

\section{Authors' contributions}

AY contributed to the design of the experiment and wrote the manuscript. TM performed the experiments and analyzed the data. $\mathrm{KH}$ and HF provided the experimental materials. All authors read and approved the final manuscript.

\section{Funding}

Not applicable.

\section{Availability of data and materials}

The datasets used and/or analyzed during the current study are available from the corresponding author on reasonable request.
Ethics approval and consent to participate

This study was approved by the Ethics Committee of Kyushu University (Approval No. 277). All subjects of this study gave their written informed consent to participate in this study.

\section{Consent for publication}

Not applicable.

\section{Competing interests}

The authors declare that they have no competing interests.

\section{Author details}

${ }^{1}$ Department of Human Science, Faculty of Design, Kyushu University, 4-9-1, Shiobaru, Minami-ku, Fukuoka 815-8540, Japan. ' La Forêt Engineering Co., Ltd, Roppongi Annex 7F, 6-7-6, Roppongi, Minato-ku, Tokyo 106-0032, Japan.

Received: 12 June 2019 Accepted: 19 August 2019

Published online: 28 August 2019

\section{References}

1. Hayashi S, Tsuru A, Kishida F, Kim Y, Higuchi S, Motomura Y. ERP study on the associations of peripheral oxytocin and prolactin with inhibitory processes involving emotional distraction. J Physiol Anthropol. 2019;38:5.

2. Tuggle AC, Cohen JH, Crews DE. Stress, migration, and allostatic load: a model based on Mexican migrants in Columbus, Ohio. J Physiol Anthropol. 2018:37:28.

3. Hasegawa J, Suzuki H, Yamauchi T. Impact of season on the association between muscle strength/volume and physical activity among communitydwelling elderly people living in snowy-cold regions. J Physiol Anthropol. 2018;37:25.

4. Logan AC, Prescott SL, Haahtela T, Katz DL. The importance of the exposome and allostatic load in the planetary health paradigm. J Physiol Anthropol. 2018:37:15

5. Yasukochi $Y$, Nishimura T, Motoi M, Watanuki S. Association of EGLN1 genetic polymorphisms with $\mathrm{SpO}_{2}$ responses to acute hypobaric hypoxia in a Japanese cohort. J Physiol Anthropol. 2018;37:9.

6. Maeda T. Relationship between maximum oxygen uptake and peripheral vasoconstriction in a cold environment. J Physiol Anthropol. 2017;36:42.

7. Katsuura K, Lee S. A review of the studies on nonvisual lighting effects in the field of physiological anthropology. J Physiol Anthropol. 2019;38:2.

8. Lee S, Kakitsuba N, Katsuura T. Do green-blocking glasses enhance the nonvisual effects of white polychromatic light? J Physiol Anthropol. 2018;37:29.

9. Kozaki T, Hidaka Y, Takakura J, Kusano Y. Suppression of salivary melatonin secretion under 100-Hz flickering and non-flickering blue light. J Physiol Anthropol. 2018:37:23.

10. Bjørnstad S, Patil GG, Raanaas RK. Nature contact and organizational support during office working hours: benefits relating to stress reduction, subjective health complaints, and sick leave. Work. 2016;53(1):9-20.

11. Beute F, de Kort Y. Salutogenic effects of the environment: review of health protective effects of nature and daylight. Appl Psychol Health Well Being. 2014:6:67-95.

12. Aries MBC, Veitch JA, Newsham GR. Windows, view, and office characteristics predict physical and psychological discomfort. J Environ Psychol. 2010;30:533-41.

13. Heerwagen $\mathrm{JH}$, Orians $\mathrm{GH}$. Adaptations to windowlessness: a study of the use of visual decor in windowed and windowless offices. Environ Behav. 1986;18(5):623-39.

14. Berman M, Jonides J, Kaplan S. The cognitive benefits of interacting with nature. Psychol Sci. 2008;19:1207-12.

15. Yasukouchi A, Toda N, Noguchi H. Optimal lighting conditions for office workers from the perspective of non-visual effects. Int Confer Occupational Health and Safety (ICOHS-2017). Bali: KnE Life Sciences; 2018. p. 451-61.

16. Bringslimark T, Hartig T, Patil GG. Adaptation to windowlessness: do office workers compensate for a lack of visual access to the outdoors? Environ Behav. 2011:43(4):469-87.

17. Finnegan MC, Solomon LZ. Work attitudes in windowed vs. windowless environment. J Soc Psychol. 1981;115:291-2.

18. Canazei M, Laner M, Staggl S, Pohl W, Ragazzi P, Magatti D, Martinelli E, Di Trapani P. Room- and illumination-related effects of an artificial skylight. Lighting Res Technol. 2015;0:1-20. 
19. Amundadottir ML, Rockcastle S, Khanie MS, Andersen M. A human-centric approach to assess daylight in buildings for non-visual health potential, visual interest and gaze behavior. Build Environ. 2017;113:5-21.

20. Benedetti M, Motamed A, Deschamps L, Scartezzini JL. On the integration of non-image-forming effects of light on venetian blinds and electric lighting control. In: Scartezzini JL, editor. Cisbat 2017 Int Confer Future Buildings \& Districts - Energy Efficiency from Nano to Urban Scale, vol. 122: Energy Procedia; 2017. p. 1039-44.

21. Konis K. A novel circadian daylight metric for building design and evaluation. Build Environ. 2017;113:22-38.

22. Mills PR, Tomkins SC, Schlangen $\amalg$. The effect of high correlated colour temperature office lighting on employee wellbeing and work performance. J Circadian Rhythms. 2007:5:2.

23. van Bommel WJ. Non-visual biological effect of lighting and the practical meaning for lighting for work. Appl Ergon. 2006;37(4):461-6.

24. Moore RY, Lenn NJ. A retinohypothalamic projection in the rat. J Comp Neurol Res Syst Neurosci. 1972;146(1):1-14.

25. Lewy AJ, Wehr TA, Goodwin FK, Newsome DA, Markey SP. Light suppresses melatonin secretion in humans. Science. 1980;210:1267-9.

26. Brainard G, Hanifin J, Greeson J, Byrne B, Glickman G, Gerner E, Rollag MD. Action spectrum for melatonin regulation in humans: evidence for a novel circadian photoreceptor. J Neurosci. 2001;21(16):6405-12.

27. Thapan K, Arendt J, Skene DJ. An action spectrum for melatonin suppression: evidence for a novel non-rod, non-cone photoreceptor system in humans. J Physiol. 2001;535:261-7.

28. Berson DM, Dunn FA, Takao M. Phototransduction by retinal ganglion cells that set the circadian clock. Science. 2002;295:1070-3.

29. CIE T, Report. Ocular lighting effects on human physiology and behaviour. 2004.

30. Lucas RJ, Peirson SN, Berson DM, Brown TM, Cooper HM, Czeisler CA, Figueiro MG, Gamlin PD, Lockley SW, O'Hagan JB, Plice LLA, Provencio I, Skene DJ, Brainard GC. Measuring and using light in the melanopsin age. Trends Neurosci. 2014;37(1):1-9.

31. Higuchi S, Motohashi Y, Liu Y, Maeda A. Effects of playing a computer game using a bright display on presleep physiological variables, sleep latency, slow wave sleep and REM sleep. J Sleep Res. 2005;14:267-73.

32. Walter WG, Cooper R, Aldridge VJ, McCallum WC, Winter AL. Contingent negative variation: an electric sign of sensori-motor association and expectancy in the human brain. Nature. 1964;203:380-4.

33. Dai QP, Cai WJ, Shi W, Hao LX, Wei MC. A proposed lighting-design space: circadian effect versus visual illuminance. Build Environ. 2017;122:287-93.

34. Figueiro MGP, Nagare R, Price LLA. Non-visual effects of light: how to use light to promote circadian entrainment and elicit alertness. Lighting Res Technol. 2018;50(1):38-62.

35. Klein DC, Smoot R, Weller JL, Higa S, Markey SP, Creed GJ, Jacobowitz DM. Lesions of the paraventricular nucleus area of the hypothalamus disrupt the suprachiasmatic spinal cord circuit in the melatonin rhythm generating system. Brain Res Bull. 1983;10:647-52.

36. Higashi $H$. The effect of the store-bought LED lamps on the action prediction of circadian rhythm. J Illum Eng Inst Jpn. 2015;99(1):15-9.

37. Irwin DA, Knott JR, MCAdam DW, Rebert CS. Motivational determinants of the "contingent negative variation". Electroenceph Clin Neurophysiol. 1966; 21:538-43.

38. Tecce JJ. Contingent negative variation (CNV) and psychological processes in man. Psychol Bull. 1972;77(2):73-108.

39. Van Olst EH, Orlebeke JF, Fokkema SD. Skin conductance as a measure of tonic and phasic arousal. Acta Physiologica. 1967;27:262.

40. Kuller R, Wetterberg L. Melatonin, cortisol, EEG, ECG and subjective comfort in healthy humans: impact of two fuorescent lamp types at two light intensities. Lighting Res Technol. 1993;25(2):71-81.

41. Sato M, Yasukouchi A. In: Sato M, Tokura H, Watanuki S, editors. Non-visual effects of room illumination. Fukuoka: Kyushu University Press; 1999. p. 3-10.

42. Noguchi H, Sakaguchi T. Effect of illuminance and color temperature on lowering of physiological activity. Appl Human Sci. 1999;18(4):117-23.

43. Cajochen C. Alerting effect of light. Sleep Med Rev. 2007;11:453-64.

44. Chellappa SL, Steiner R, Blattner P, Oelhafen P, Gotz T, Cajochen C. Nonvisual effects of light on melatonin, alertness and cognitive performance: can blue-enriched light keep us alert? PloS One. 2011;6(1):e16429.

45. Yasukouchi A, Ishibashi K. Non-visual effects of the color temperature of fluorescent lamps on physiological aspects in humans. J Physiol Anthropol Appl Human Sci. 2005;24(1):41-4.
46. Deguchi T, Sato M. The effect of color temperature of lighting sources on mental activity level. Ann Physiol Anthrop. 1992;11(1):37-43.

47. Iwakiri K, Watanuki S, Yasukouchi A, Tochihara Y. The effect and after-effect of light-source color on early component of CNV. Jpn J Physiol Anthrop. 1997;2:31-7

48. Iwakiri K, Yasukouchi A. The effects of color temperature and color rendering properties of light sources on arousal level. Jpn J Physiol Anthrop. 1997;2:173-8

49. Rea MS, Figueiro MG, Bierman A, Hamner R. Modelling the spectral sensitivity of the human circadian system. Lighting Res Technol. 2012;44: 386-96.

50. Mukae $H$, Sato M. The effect of color temperature of lighting sources on the autonomic nervous functions. Ann Physiol Anthrop. 1992;11(5):533-8.

51. Ishibashi K, Kitamura S, Kozaki T, Yasukouchi A. Inhibition of heart rate variability during sleep in humans by $6700 \mathrm{~K}$ pre-sleep light exposure. J Physiol Anthropol. 2007;26(1):39-43.

52. Kobayashi $\mathrm{H}$, Sato M. Physiological responses to illuminance and color temperature of lighting. Ann Physiol Anthrop. 1992;11(1):45-9.

53. Morita K, Tokura H. Effects of lights of different color temperature on the nocturnal changes in core temperature and melatonin in humans. Appl Human Sci. 1996;15(5):243-6.

54. Yasukouchi A, Yasukouchi Y, Ishibashi K. Effects of color temperature of fluorescent lamps on body temperature regulation in a moderately cold environment. J Physiol Anthropol Appl Human Sci. 2000;19(3):125-34.

55. Kozaki T, Kubokawa A, Taketomi R, Hatae K. Light-induced melatonin suppression at night after exposure to different wavelength composition of morning light. Neurosci Lett. 2016;11(616):1-4.

56. Kozaki T, Toda N, Noguchi H, Yasukouchi A. Effects of different light intensities in the morning on dim light melatonin onset. J Physiol Anthropol. 2011;30(3):97-102.

57. Studer P, Brucker JM, Haag C, Van Doren J, Moll GH, Heinrich H, Kratz O. Effects of blue- and red-enriched light on attention and sleep in typically developing adolescents. Physiol Behavior. 2019;199:11-9.

58. Kozaki T, Miura N, Takahashi M, Yasukouchi A. Effect of reduced illumination on insomnia in office workers. J Occup Health. 2012:54:331-5.

59. Lee SL, Matsumori K, Nishimura K, Nishimura Y, Ikeda Y, Eto T, Higuchi S. Melatonin suppression and sleepiness in children exposed to blue-enriched white LED lighting at night. Physiol Rep. 2018;6(24):e13942.

60. Xie Z, Chen F, Li WA, Geng X, Li C, Meng X, Feng Y, Liu W, Yu F. A review of sleep disorders and melatonin. Neurol Res. 2017;39(6):559-65.

61. Kozaki T, Kitamura S, Higashihara Y, Ishibashi K. Effect of color temperature of light sources on slow-wave sleep. J Physiol Anthropol Appl Human Sci. 2005;24(2):183-6.

62. Cajochen C, Krauchi K, Wirz-Justice A. Role of melatonin in the regulation of human circadian rhythms and sleep. J Neuroendocrinol. 2003;15(4):432-7.

63. Vetter C, Juda M, Lang D, Phys D, Wojtysiak A, Roenneberg T. Blue-enriched office light competes with natural light as a zeitgeber. Scand J Work Environ Health. 2011:37(5):437-45.

\section{Publisher's Note}

Springer Nature remains neutral with regard to jurisdictional claims in published maps and institutional affiliations.

Ready to submit your research? Choose BMC and benefit from

- fast, convenient online submission

- thorough peer review by experienced researchers in your field

- rapid publication on acceptance

- support for research data, including large and complex data types

- gold Open Access which fosters wider collaboration and increased citations

- maximum visibility for your research: over $100 \mathrm{M}$ website views per year

At BMC, research is always in progress.

Learn more biomedcentral.com/submissions 